Article

\title{
Impacts of the Increasingly Strict Sulfur Limit on Compliance Option Choices: The Case Study of Chinese SECA
}

\author{
Lixian Fan $(\mathbb{D}$ and Bingmei Gu *(1) \\ School of Management, Shanghai University, Shanghai 200444, China; lixianfan@shu.edu.cn \\ * Correspondence: gubingmei163@163.com; Tel.: +86-021-6613-7696
}

Received: 23 November 2019; Accepted: 19 December 2019; Published: 24 December 2019

\begin{abstract}
The International Maritime Organization (IMO) has proposed several environmental regulations on controlling $\mathrm{SO}_{\mathrm{x}}$ and $\mathrm{NO}_{\mathrm{x}}$ emissions from ships in coastal areas. Under the framework of IMO, some areas have established strict emission control areas (ECAs) to reduce emissions, which mainly contain Europe and North America. To further strengthen the control and supervision over air pollutants from shipping activities, the Sulfur cap regulation of $0.5 \%$ by mass will come into effect on 1 January, 2020 globally, when all the sailing vessels on the high sea should use fuels with sulfur content less than $0.5 \%$. This limit is stricter for the global recognized sulfur emission control areas (SECAs), where it was $0.1 \%$ since 1 January 2015. However, Chinese local SECA lags behind the globally recognized SECAs, where the $0.5 \%$ Sulfur cap was implemented from 2016 and it has to be strengthened along with the global sulfur cap 2020. These increasingly stringent emission regulations have huge effects on shipping operators. The current study discusses the potential impacts of the stricter sulfur cap on operators' compliance option choices, where fuel-switching and scrubber system are analyzed under different sulfur limits. Meanwhile, the slow steaming practice is incorporated into the fuel-switching option by considering speed differentiation in different sulfur limit areas. This study develops a cost-minimizing model using NPV (net present value) method. It analyzes the optimal option within vessels' lifespan considering the tradeoff between the initial investment and future operational cost for newbuilding vessels based on a case study. In addition, emissions of $\mathrm{CO}_{2}$ and $\mathrm{SO}_{\mathrm{x}}$ are compared under different compliance options in different sulfur cap scenarios. Our results find that the scrubber system is a suitable option to comply with the $0.5 \%$ global sulfur limit, and a higher efficiency of sulfur abatement can be attained by the scrubber system option. However, it emits more carbon emissions due to higher energy consumption used by the scrubber system. In addition, the effects of additional vessels deployed in the cycle on the compliance choices are also demonstrated in the analysis.
\end{abstract}

Keywords: shipping industry; compliance option; SECA; sulfur limit; emission reduction

\section{Introduction}

Over the past century, international maritime transport has been the main mode of transportation for global trade and one of the bridges of globalization development [1,2]. Transportation sector accounts for a significant part of greenhouse gas (GHG) emissions, which was estimated at about $20.4 \%$ during 2014, whereas the maritime sector accounted for $2.2 \%$ [3]. However, the rapid development in the shipping industry also poses several threats into human beings. Given that nearly $70 \%$ of the global emissions due to shipping activities occurs within $400 \mathrm{~km}$ from land, ship exhaust pollution poses more serious threats to coastal areas and port waters [4]. It is said that the air pollution from ocean-going vessels is responsible for around 60,000 cardiopulmonary globally and lung cancer deaths of about 
15,000-20,000 deaths in East Asia [5]. In addition to these, engines of marine transportation use the cheapest fuels, i.e., heavy fuel oil (HFO), which generates more sulfur emissions due to the higher sulfur content. Therefore, sulfur emissions from shipping activities has drawn significant attention in practice and academia [6-8].

Sustainability in shipping development is of critical importance to environmental protection and human health [2]. Globally, emissions from shipping activities are regulated by IMO, whose aims incorporate environment protection through reducing pollution caused by ships. For the purpose of emission abatement from shipping industry, IMO combined with some other regional bodies have taken active actions on different issues. One of them is establishing emission control areas (ECAs), which was first proposed in Annex VI of the 1997 MARPOL (International Convention for the Prevention of Pollution from Ships) protocol. Nowadays, the globally recognized ECAs include four main parts-i.e., Baltic Sea area, the North Sea area, the North American area, and the Unites States Caribbean sea area-which became effective since 1 January, 2015 [9]. In detail, IMO is pursuing control of marine emissions by two approaches: a) vigorous controls inside ECAs; b) global limits for sulfur and NOx emission limits [10], by impending global cap in sulfur content demands all the vessels use fuel with sulfur content less than $0.5 \%$ from 1 January 2020. Meanwhile, China also has issued local SECA policies for ships since 1 January 2016. However, Chinese SECA policy is incongruent with the other existing SECAs in standard and range, i.e., with a $0.5 \%$ Sulfur content limit and $12 \mathrm{~nm}$ from the coastal baseline for regulatory areas [4].

The following Figure 1 illustrates the different regulations on Sulfur content limit among IMO regulations and the Chinese SECA. The latest Sulfur limit in IMO recognized SECAs is $0.1 \%$ from 1 January 2015, which means that the fuel with Sulfur content less than $0.1 \%$ by mass or any other approved apparatus should be used to limit $\mathrm{SO}_{x}$ emissions. Chinese SECA policy started relatively late and the control of sulfur emissions from ships is also lagging behind, which is inconsistent with the other globally recognized SECAs. The global sulfur limit and Chinese SECA will be identical after 2020, which makes the enforcement of Chinese SECA unnecessary. Some researchers argued that China's regulations of SECA should comply with international standards accordingly, which means that a stricter standard should be established [3,4,11-14] Therefore, the Chinese government is negotiating a stricter sulfur limit for its SECA, which makes it necessary to investigate the impacts of this increasingly stricter sulfur policy in China. In addition, operators and researchers have to consider the effects of changing policies on shipping operations [6,11]. Besides, IMO requires that all the newbuilding vessels from 2016 through North American ECA must reduce NOx emissions by $75 \%$. The Energy Efficiency Design Index (EEDI) was included in MARPOL Annex VI from 2020 for $\mathrm{CO}_{2}$ emissions per mile based on ship design and engine performance [1].

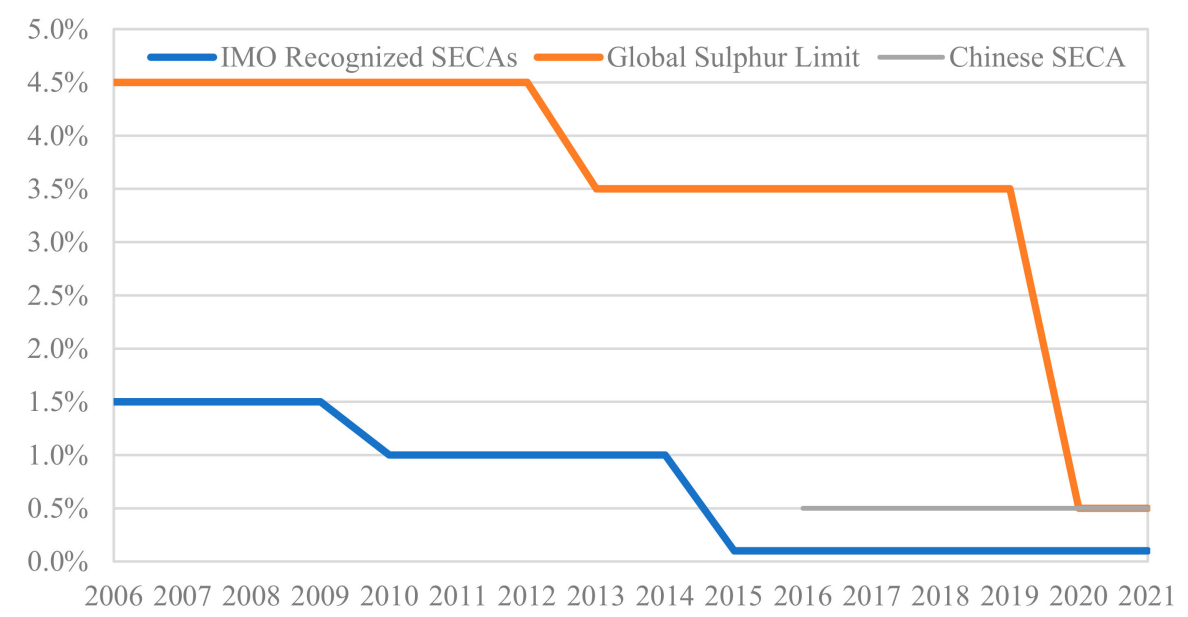

Figure 1. Comparison among China and IMO sulfur regulation standards. 
From the perspective of operators, the increasingly stringent sulfur cap will bring considerable challenges, because they must choose a feasible way to comply with sulfur regulations [13]. Currently, the most realistic approaches to reduce sulfur exhaust are the following three options. The first one is switching to low-sulfur oil when sailing in regulatory areas. Specifically, use of marine gas oil (MGO) within global SECAs of the $0.1 \%$ sulfur cap, and ultra-low-sulfur fuel oil (ULSFO; sulfur content less than $0.5 \%$ by mass) within $0.5 \%$ sulfur limit areas as well as HFO for areas with a $3.5 \%$ sulfur cap. It is worthwhile mentioning that the price of low-sulfur oil is higher than that of high-sulfur fuel, therefore more operating costs should be paid with the fuel-switching option. The second option is installing the scrubber system which removes most sulfur content from exhaust, meanwhile enables operators continuous use of cheap oil with high-sulfur content [10]. However, in addition to the high initial investment cost, the scrubber system also needs additional annual maintenance and operating costs. Therefore, extra energy will be used with the scrubber system option. The last one is using liquefied natural gas (LNG), which is a very clean propulsion fuel. It can not only satisfy the Sulfur regulation, but also reduce NOx, PM, and $\mathrm{CO}_{2}$ emissions [14]. However, the LNG option needs considerable initial investment and there are supply limitations at ports [15]. In this study, the LNG system is out of our discussion due to its non-comparability of emission abatement with the other alternatives [16].

Slow steaming within SECAs is a possible way to minimize bunker cost owing to the higher price of low-sulfur oil [17]. From the viewpoint of operators, the reason of slow steaming is the nonlinear relationship between speed and fuel consumption as well as the large price spread between different sulfur content oils. If operators choose the fuel-switching option, the bunker used inside the globally recognized SECAs should be that with sulfur content less than $0.1 \%$ by mass, while less than $0.5 \%$ outside SECAs from 2020 [18]. Due to the price spread between low- and high-sulfur oils, saving costs by slow steaming is a feasible option. Considering the speed differentiation in the fuel-switching and constant speed in the scrubber system, the choices of compliance options are explored under different sulfur limit scenarios based on a case study. Besides, the impacts of extra deployed vessels on the sulfur compliance options are also analyzed based on a cost-minimizing model.

Whether the increasingly stringent sulfur limit will influence choices on sulfur compliance is our main focus. Commonly, investment is a critical and long-term decision-making. From the viewpoint of shipowners or operators, cost-efficiency of compliance options is high on the agenda. To adopt the scrubber system in a ship, a major investment cost occurs at the beginning of the project, which saves more energy costs during the operational period in comparison with the long-term operating costs of the fuel-switching option. Therefore, the tradeoffs between the initial investment and future operating costs will be their critical considering elements. Hence, the corresponding investments during its lifespan need to be transformed into a suitable form, i.e., net present value (NPV), which is a commonly used financial approach in investment evaluation and it can help consider the initial investment and future operating costs in compliance option choices during the vessel's lifespan. To overcome its drawback of failing to evaluate the ethical aspects of transport policies [19], the efficiency of emission abatement for two alternatives is taken into consideration in this study.

The objective of this study is to discuss the impacts of sulfur limit on compliance methods (fuel-switching or scrubber system) for newbuilding vessels using NPV analysis. Meanwhile, the speed differentiation is considered in the fuel-switching option with a cost-minimizing model. The contributions of the study can be demonstrated as follows. First, the increasingly strict sulfur limit in Chinese SECA and global sulfur limit is explored. Different scenarios with various sulfur limits are explored by the proposed model, which incorporates the initial investment and future operating costs. This can help operators decide to whether to invest sulfur abatement equipment or not. Second, the slow steaming practice is considered in the fuel-switching option, which can accurately simulate the responses of operators during the ship's lifetime. Third, the emissions of $\mathrm{CO}_{2}$ and $\mathrm{SO}_{\mathrm{x}}$ are compared under different compliance options in different sulfur limit scenarios. By doing this, the effectiveness of sulfur caps and compliance options can be examined for policy-makers and operators, respectively. 
The structure of the paper is as follows. Section 2 reviews the related studies. Section 3 introduces the methodology used in this study. Section 4 presents a case study to compare the compliance options of operators under different sulfur limit scenarios. Section 5 concludes the study and proposes the future directions.

\section{Literature Review}

Sustainable shipping is an active topic due to the hottest discussion of GHG, which has recently attracted increasing focuses of both practitioners and researchers due to its negative impacts on the environment and human health [20-23]. In the following, the related studies are mainly reviewed from three aspects: (1) impacts of SECA on the shipping industry, (2) emission abatement methods from ships, (3) emission regulations for maritime.

\subsection{Impacts of SECA on the Shipping Industry}

Researchers have been very active in the discussion of SECAs, because it has great impacts on the shipping industry. Schinas and Stefanakos [24] provided a methodological framework for costs assessment of some environmental measurements, in which the SECA measure is considered as increasing the operating expenses of sailing vessels due to the required sulfur limit. They conducted a stochastic linear programming to minimize operator's total costs by determining the fleet-mix and the capacity. With the enforcement of the sulfur limit regulation, many scholars studied its impacts from the perspective of operators, such as Schinas and Stefanakos [25] and Abadie et al. [26]. In addition, Chang et al. [27] explored the impacts of ECAs on port efficiency, using two-stage approaches to examine whether sulfur and nitrogen regulations harm the efficiency of ports. Their results indicated that such regulations can harm port efficiency, reflecting concerns of policy-makers and industrial managers. In order to investigate the effects of sulfur limit on cruise shipping, Zhen et al. [12] developed a mixed integer programming model to manage voyage plans by optimizing speeds, sailing patterns, and call sequences, which can minimize the fuel costs inside and outside SECAs. Using inverse data envelopment analysis (IDEA) model, Lin et al. [28] discussed the resource consumption and efficiency in some Chinese ports, whose data from 16 main ports were examined using IDEA and the 13th Five-Year Plan in China. Importantly, they confirmed that the method is a feasible way to evaluate port performance, and their study helped policymakers to optimize resource of container ports.

In addition to the aforementioned research, other issues were also illustrated in the impacts of SECA on the shipping industry. With the demand of low-sulfur fuel increasing, due to SECA regulations, the fuel prices will potentially increase, which could result in closures of some unprofitable services due to the loss of market from higher freight rates and incremental operational costs [3]. Zis and Psaraftis [29] discussed the implication of the new sulfur limits on the European Ro-Ro sector. They argued that the increased operating costs paid by Ro-Ro operators within SECAs owing to the stricter limits can lead to the shutting down of some routes and a redistribution of cargo flows with land-based alternatives. Chen et al. [5] investigated the impacts of SECAs on global shipping, using data on the Asia-Europe route to model the route-choosing decision of liner shipping though the potential SECA in the Mediterranean Sea. They revealed that if the new SECA was established in this area, considerable ships would re-route to escape the SECA limit under certain conditions.

The recent literature has been extended to include the sulfur limit in the shipping industry, and most of them analyzed the impacts of SECA on the shipping industry especially on operators. However, few of them have discussed the impacts of the increasingly strict sulfur limits on operators' compliance option choices. Furthermore, none of them demonstrates the strict sulfur limit within Chinese SECA. In the study, the impacts of changing sulfur cap on operators' compliance option choices are explored by considering global and Chinese sulfur caps in the future. The results of this study can help operators flexibly choose their compliance options under the increasingly strict sulfur limit regulation in the shipping industry. 


\subsection{Emission Abatement Methods from Ships}

There are a number of compliance methods available for emission reduction; such as use of low-sulfur fuel oils or LNG, HFO with scrubber and selective catalytic reactor (SCR), humid air motor (HAM), exhaust gas recirculation (EGR), and direct water injection (DWI) [10]. As discussed above, there are three main compliance options for sulfur abatement, i.e., MGO, scrubber system and LNG [30,31]. Using life cycle assessment, Brynolf et al. [32] presented three compliance options for sulfur and NOx, i.e., HFO combined with SCR and scrubber, MGO combined with SCR and LNG. They found that none of them can significantly reduce greenhouse gas in the ship's life cycle comparing with HFO. Furthermore, Zis and Psaraftis [3] proposed several options for mitigating negative impacts of emissions, which includes speed reduction, change of service frequency, use of LNG, scrubber investment, and so on. Based on NPV method, Jiang et al. [33] examined the cost-benefit of scrubber system and MGO by combining private costs with social benefits. In addition to the aforementioned options, from the viewpoint of sustainability in shipping activities, Zis [34] discussed the potential and prospects of cold ironing as an abatement emission option, which mainly used on auxiliary engines at berth. They examined that there were economic motivations for operators to adopt cold ironing with medium and high low-sulfur oil price scenarios.

Some other researchers considered various emission types in addition to sulfur emissions. Ammar and Seddiek [35] compared the MGO with EGR measures and LNG to comply with the $\mathrm{NO}_{\mathrm{x}}$ and $\mathrm{SO}_{\mathrm{x}}$ emission regulations in the same time. Their results indicated that LNG is the optimum option from environmental and economic points of view. Different with the other studies, Winebrake et al. [16] examined marine emissions by well-to-propeller analysis, which analyzed the fuel emissions from production to distribution. Their results showed that the natural-gas fuel can provide environmental benefits for local residents compared to distillate fuel in the short term, but in the long-run methane leaks will lead to extra global warming. Yang et al. [36] explored control methods of $\mathrm{NO}_{\mathrm{x}}$ and $\mathrm{SO}_{\mathrm{x}}$ using expert opinion and proposed a hybrid multiple attribution decision-making approach for ranking options in new vessels, they found that continuous water injection is the best way to control $\mathrm{NO}_{\mathrm{x}}$ considering cost elements. In terms of $\mathrm{SO}_{\mathrm{x}}$ control options, they argued that fuel-switching and segregated tank design are better than the others. Abadie et al. [26] discussed the economic assessment of fuel-switching and scrubber installation in existing vessels under uncertainty. They also considered the possibility of an unexpected change from a non-ECA sea to an ECA navigation area. More importantly, the more fuel consumption used by scrubbers was conducted in their research, in which additional $\mathrm{CO}_{2}$ emissions and how they influence the financial analysis are discussed. However, other alternatives such as slow steaming were not considered in their study. Different with previous studies, this study tries to explore the compliance option choices of operators in new-building vessels by taking the slow steaming of fuel-switching into consideration. It not only compares the $\mathrm{CO}_{2}$ emissions, but also discuss the $\mathrm{SO}_{\mathrm{x}}$ emissions under two different options.

In addition to the above-mentioned studies, some researchers have analyzed the effects of slow steaming on emission abatement [11,34,36,37]. Doudnikoff and Lacoste [14] examined the effects of speed reduction inside SECAs by solving a cost-minimizing model with heuristic approach. They found that slow steaming within SECAs slightly decreases operators' total costs and increases $\mathrm{CO}_{2}$ emissions. Fan and Huang [11] discussed the slow steaming inside the Chinese SECA, which demonstrated the effectiveness of the Chinese sulfur limit. To summarize, slow steaming is an economic method to save energy costs due to the big price spread between low-and high-sulfur bunkers, hence slow steaming is necessary to be considered in the fuel-switching option. To the authors' best knowledge, several studies have discussed the compliance options of fuel-switching and scrubber system, but few of them have considered the slow steaming practice inside SECAs. Therefore, this study tries to fill the gap by considering slow steaming for operators adopting the fuel-switching option. 


\subsection{Emission Regulations for Maritime}

Recently, the discussion on shipping regulations is active, especially on the upcoming 2020 global sulfur cap. Among them, the SECA policy aims to mitigate the air pollution from shipping activities near coast areas by adopting more stricter standards of emissions from ships. Gu et al. [38] necessitated the maritime fuel management for shipping companies with business in SECAs. Along with the globally recognized SECAs, some other SECAs are under discussion. Panagakos et al. [39] discussed the potential SECA of Mediterranean Sea and examined its effects on model shifts using a case study. They found that the designation of Mediterranean SECA will lead to a modal shift to road-only route by $5.2 \%$. Furthermore, Chang et al. [7] focused on the potential ECA in Asia, i.e., Port of Incheon in Korea which has the most densely populated coastal areas. They claimed that the ECA designation in this area is of paramount significance for the region and other regions that are in similar conditions. China also issued its domestic SECA lately, in which the control of sulfur emissions from ships was relatively relaxed. China's $0.5 \%$ sulfur limit within SECA has been implemented on 1 January, 2019, which is same as the global limit set by IMO after 2020. However, there is still a gap between Chinese SECA and the other globally recognized SECAs [4].

In addition to the ECA regulations, other policies were also discussed to reduce emissions from shipping activities. Cariou and Cheaitou [40] compared the effectiveness of the European speed limit and the bunker-levy policy to reduce $\mathrm{CO}_{2}$ emissions, and their results indicated that speed limit policy is not an optimal strategy due to more emissions paid by the society. Halim et al. [1] examined the required supporting policy measures for the decarbonization goal of Paris Agreement, which includes increasingly stricter energy efficiency targets, low-carbon fuel standard and speed limit. Furthermore, market-based measures for GHG were discussed by researchers, such as Psaraftis [41], Nikopoulou et al. [42], and Wang et al. [43]. Koesler et al. [44] discussed the emission trading scheme (ETS) in the shipping industry and argued that the ETS has the potential to make the maritime sector more cost-efficient. The potential effects of maritime ETS were identified and investigated using empirical analysis of several shipping operators.

Summarizing the aforementioned papers, to the scope of our knowledge, less attention has been put on the impacts of the upcoming global sulfur cap and the increasingly stringent limit in Chinese SECA on the choice of compliance options. Furthermore, seldom of them take speed differentiation into account for the fuel-switching option. Most of the work associated with sulfur compliance choices focused on the effects and costs of different strategies but failed to consider the operating condition. Whether slow steaming inside SECAs will change operators' responses to sulfur cap regulation is one of our research objectives. In addition, sulfur and carbon emissions from fuel-switching and scrubber system options will be explored to compare their efficiency of emission abatement.

\section{Model Establishment}

\subsection{Assumptions}

Our research is based on the following assumptions:

1. Vessels adopting the fuel-switching option can utilize different bunkers for their main engines according to different sulfur cap regulations, and MGO is used in the whole voyage for auxiliary engines. It is different for the scrubber system option, where HFO can be used in anywhere combined with the chemical-based system.

2. The daily fuel consumption is proportional to the third power of the sailing speed.

3. The earnings of the liner service are related to vessels' capacity, freight rate of the specific route, vessels' loading factor and the adopted Sulfur compliance option.

4. Vessels operate in the same service choose an identical compliant option.

5. The emission abatement efficiency of the scrubber system depends on the sulfur content before and after filtering. 
6. A weekly frequency of the liner service should be kept.

\subsection{Parameters}

Similar to Fan and Huang [11], the following parameters of Table 1 are used in the model. It is noteworthy that the index $i=1$ and $i=2$ are used to indicate fuel-switching and scrubber system options, respectively. Besides, subscript $k$ expresses the specific sulfur limit in global SECAs (G), Chinese SECA (C), and non-SECAs (N).

Table 1. Parameter Descriptions

\begin{tabular}{|c|c|}
\hline$D$ & Round-Trip Distance (Nautical Miles) \\
\hline$D^{S E C A}$ & Total distance inside SECAs in the voyage (nautical miles) \\
\hline$D^{G-S E C A}$ & Total distance inside global SECAs in the voyage (nautical miles) \\
\hline$D^{C-S E C A}$ & Total distance inside Chinese SECA in the voyage (nautical miles) \\
\hline$V_{0}$ & Design speed (knots) \\
\hline$V^{S}$ & Constant speed along the voyage for a given number of operating vessels \\
\hline$V^{G-S E C A}$ & The sailing speed within global SECAs with fuel-switching (knots) \\
\hline$V^{C-S E C A}$ & The sailing speed within Chinese SECA with fuel-switching (knots) \\
\hline$V^{N-S E C A}$ & The sailing speed beyond SECAs with fuel-switching (knots) \\
\hline$P$ & Unavoidable port time during the voyage (day) \\
\hline$S$ & The cruising time in the voyage $(\mathrm{h})$ \\
\hline$T$ & Total time for a voyage $(\mathrm{h})$ \\
\hline$S^{S E C A}$ & The cruising time inside SECAs along the voyage $(\mathrm{h})$ \\
\hline$N$ & Number of vessels sailing along the voyage \\
\hline$F_{k}^{M}$ & The daily bunker consumption of the main engine (tons/day) \\
\hline$F^{k}$ & Average daily fuel consumption of the main engine on the voyage (tons/day) \\
\hline$F^{A}$ & Daily consumption of the auxiliary engine on the voyage (tons/day) \\
\hline$C_{v}$ & $\begin{array}{l}\text { Fixed daily costs of a sailing vessel, including crew, insurance, store and lubes, repair and } \\
\text { maintenance, and administration and capital costs (USD/day) }\end{array}$ \\
\hline$C_{h}^{k}$ & Price of different bunkers (USD/ton) \\
\hline$C B_{d, i}^{M}$ & Average daily fuel costs of the main engine along the voyage (\$/day) \\
\hline$C B_{d, i}^{A, i}$ & Average daily fuel costs of the auxiliary engine along the voyage (\$/day) \\
\hline$C V_{d}^{a, l}$ & Average daily fixed costs of sailing vessels along the voyage (\$/day) \\
\hline$C T_{d, i}$ & Average daily total costs of sailing vessels along the voyage (\$/day) \\
\hline Coper & Average daily operating costs of scrubber system (\$/day) \\
\hline$C T_{i}$ & Annual total costs of all sailing vessels along the voyage (\$/year) \\
\hline$E_{i}^{j}$ & Average daily emissions of vessels operating on the cycle (tons/day), $\mathrm{j}=\mathrm{CO}_{2}$ or $\mathrm{SO}_{\mathrm{x}}$ \\
\hline$C^{\text {main }}$ & Annual maintenance costs (\$/year) \\
\hline$V$ & Capacity of a vessel (TEU) \\
\hline$L$ & Loading factor of the regular voyage (\%) \\
\hline$F R$ & Freight rate of the route $(\$ / T E U)$ \\
\hline$B_{i}$ & Annual earnings of the voyage (\$) \\
\hline$\pi_{i}$ & Annual profits of the voyage (\$) \\
\hline$r$ & Discount rate \\
\hline$\eta_{k}$ & Sulfur abatement efficiency of scrubber in different areas \\
\hline$\zeta_{j}^{k}$ & Emission factor of different bunkers \\
\hline
\end{tabular}

In the paper, we consider speed differentiation inside and outside SECAs if the fuel-switching option is chosen. For the scrubber system option, a constant speed is assumed due to the continuous use of HFO.

Referring to Doudnikoff and Lacoste [17], the following equations can be attained.

$$
S^{S E C A}=\frac{D^{G-S E C A}}{V^{G-S E C A}}+\frac{D^{C-S E C A}}{V^{C-S E C A}}
$$




$$
\begin{gathered}
S-S^{S E C A}=\frac{D-D^{G-S E C A}-D^{C-S E C A}}{V^{N-S E C A}} \\
T=S+P \\
W=\frac{T}{7 * 24}=\frac{S+P}{168} \\
V^{S}=\frac{D}{(168 N-P)}
\end{gathered}
$$

To maintain a weekly service along the voyage, the number of ships in the voyage $(N)$ must equal the operating cycle length in weeks $(W)$. Hence, we have $N=W$, where $N$ and $W$ must be integers.

\subsection{Costs Composition}

From the standpoint of operators, profit-maximization is their main concern. As stated above, many scholars have proved that the slow steaming approach can reduce their operating costs due to the nonlinear relationship between speed and fuel consumption [8,45]. Furthermore, the earnings along the voyage are related to the vessels' capacity and loading factor, freight rate of the service and the specific compliance options. Actually, the optimization problem can be transferred into a cost minimization problem by minimizing the average total annual costs in the voyage $\left(C T_{i}\right)$. The total daily costs are the summation of daily energy costs for engines and fixed costs, then we have

$$
S^{S E C A}=\frac{D^{G-S E C A}}{V^{G-S E C A}}+\frac{D^{C-S E C A}}{V^{C-S E C A}}
$$

\subsection{Average Daily Total Costs for Vessels Operating in the Voyage with the Fuel-Switching Option}

In this study, if the fuel-switching option is chosen, the MGO should be used within SECAs with $0.1 \%$ sulfur limit and ULSFO with sulfur limit of $0.5 \%$, and HFO can be used if the sulfur limit is $3.5 \%$ by mass for the main engine. During auxiliary engine operation, it has nothing to do with the sailing speed owing to the on-board electricity supply. Therefore, the auxiliary engine consumes fixed daily bunker costs for a particular vessel [42].

Following Doudnikoff and Lacoste [17], the fuel consumption of the main engine within SECAs equals the product of sailing time and daily specific bunker consumption inside SECAs. With regard to the consumption outside SECAs, it is the product of the sailing time and specific daily bunker consumption outside SECAs. Therefore, we can get the average daily fuel consumption of the main engine through the summation of bunker consumption in the voyage divide by the total time during the voyage:

$$
\frac{\frac{S^{G-S E C A}}{24} F_{G}^{M}+\frac{S^{C-S E C A}}{24} F_{C}^{M}+\frac{\left(S-S^{S E C A}\right)}{24} F_{N}^{M}}{\frac{T}{24}}
$$

To maintain operators' weekly service frequency, combining with Equations (3)-(4), we have the following equation on average daily fuel consumption of main engines.

$$
F^{M}=\frac{S^{G-S E C A} F_{G}^{M}+S^{C-S E C A} F_{C}^{M}+S^{N-S E C A} F_{N}^{M}}{168 N}
$$

We have the daily bunker consumption as follows.

$$
\begin{aligned}
& F_{G}^{M}=F_{0}^{M}\left(\frac{V^{G-S E C A}}{V_{0}}\right)^{3} \\
& F_{C}^{M}=F_{0}^{M}\left(\frac{V^{C-S E C A}}{V_{0}}\right)^{3}
\end{aligned}
$$




$$
F_{N}^{M}=F_{0}^{M}\left(\frac{V^{N-S E C A}}{V_{0}}\right)^{3}
$$

Similar to Fan and Huang [11], we write:

$$
F_{0}^{M}=\left(S F O C^{M} E L^{M} P S^{M}\right) \frac{24}{10^{6}}
$$

where SFOC indicates the specific fuel consumption of the engine $(\mathrm{g} / \mathrm{KW} \mathrm{h})$; and $P S$ is the engine's power; $E L$ is the engine load (\%); and the superscript $M$ represents the main engine. In this case, we adopt the following value from Corbett et al. [45]

$$
S F O C^{M}=206 \mathrm{~g} / \mathrm{kW} \mathrm{h}, E L^{M}=0.8 .
$$

Therefore, the average daily bunker costs for main engines of all the service vessels in the voyage is

$$
C B_{d, 1}^{M}=\frac{S^{G-S E C A} F_{G}^{M} C_{b}^{G}+S^{C-S E C A} F_{C}^{M} C_{b}^{C}+\left(S-S^{S E C A}\right) F_{N}^{M} C_{b}^{N}}{168}
$$

Inserting Equations (1) and (2) and Equations (10)-(12) into Equations (13), we have the following equation of average daily bunker costs of main engines, which is related to $V^{G-S E C A}$, $V^{C-S E C A}$ and $V^{N-S E C A}$.

$$
C B_{d, 1}^{M}=F_{0}^{M} \frac{D^{G-S E C A}\left(V^{G-S E C A}\right)^{2} C_{b}^{G}+D^{C-S E C A}\left(V^{C-S E C A}\right)^{2} C_{b}^{C}+\left(D-D^{S E C A}\right)\left(V^{N-S E C A}\right)^{2} C_{b}^{N}}{168 V_{0}^{3}}
$$

The average daily bunker costs of auxiliary engines, it is only composed of a fixed part, which equals

$$
\begin{gathered}
F^{A}=S F O C^{A} E L^{A} P S^{A} \frac{24}{10^{6}} \\
C B_{d, 1}^{A}=F^{A} N C_{b}^{G}
\end{gathered}
$$

where the following value is utilized: $S F O C^{A}=221 \mathrm{~g} / \mathrm{kWh}, E L^{A}=0.5$.

The daily fixed cost for operating vessels can be expressed as

$$
C V_{d}=C_{v} N
$$

\subsection{Average Daily Total Costs for All Vessels in the Voyage With The Scrubber Installation Option}

The daily total costs of the scrubber installation option consist of four parts, i.e., daily bunker costs of the main engine and auxiliary engine, fixed and operating costs for dealing with sulfur regulations. Specifically, if operators choose to install the scrubber system, vessels can sail at a constant speed due to the continuous use of HFO. Hence, the constant sailing speed can be acquired through Equation (5). Similarly, we can get the daily bunker costs for main and auxiliary engines with the scrubber installation option. Moreover, additional daily energy consumption due to the scrubber system is considered, which is denoted by a ratio of $m$. Then the final equations are

$$
\begin{gathered}
C B_{d, 2}^{M}=(1+m) F^{M}\left(\frac{D\left(V^{S}\right)^{2} C_{b}^{H F O}}{168 V_{0}^{3}}\right) \\
C B_{d, 2}^{A}=(1+m) F^{A} N C_{b}^{H F O}
\end{gathered}
$$

In terms of daily fixed costs, it is the same as that of the fuel-switching option, i.e., Equation (17). 
Commonly, the scrubber system chemically treats with sodium hydroxide or magnesium oxide to reduce sulfur pollution. Its treatment with pure seawater is equivalent to the bunker with $0.5 \%$ sulfur content, while sodium hydroxide or magnesium oxide combined with seawater correspond to the bunker with $0.1 \%$ sulfur content.

$$
C^{\text {oper }}=\frac{M \times C^{\text {chem }}}{T / 24}
$$

where $M$ is the amount of the chemical reactant used during a round-trip (tons), and $C^{\text {chem }}$ is the unit cost of the reactant $(\$ /$ ton).

Therefore, the total daily cost with the fuel-switching option is

$$
C T_{d, 2}=C B_{d, 2}^{M}+C B_{d, 2}^{A}+C_{v} N+C^{o p e r}
$$

\subsection{Emissions of the Sulfur Compliance Options}

As stated in Doudnikoff and Lacoste [17], the average amount of $\mathrm{CO}_{2}$ and $\mathrm{SO}_{\mathrm{x}}$ emissions for all the vessels can be calculated by the product of the fuel consumption and their respective emission factor. According to Equations (14)-(19), the daily emissions of $\mathrm{CO}_{2}$ and $\mathrm{SO}_{\mathrm{x}}$ are

$$
\begin{gathered}
E_{1}^{j}=F_{0}^{M} \frac{\zeta_{j}^{G} D^{G-S E C A} V^{G-S E C A^{2}}+\zeta_{j}^{C} D^{C-S E C A} V^{C-S E C A^{2}}+\zeta_{j}^{N}\left(D-D^{S E C A}\right) V^{N-S E C A^{2}}}{168 V_{0}^{3}}+\zeta_{j}^{G} F^{A} N \\
E_{2}^{C O_{2}}=\zeta_{C O_{2}}^{H}(1+m)\left(F_{0}^{M}\left(\frac{D\left(V^{S}\right)^{2}}{168 V_{0}^{3}}\right)+F^{A} N\right) \\
\left.E_{2}^{S O_{x}}=\zeta_{S O_{x}}^{H}(1+m)\left(F^{M}\left(\eta_{G} \frac{D^{G-S E C A}\left(V^{S}\right)^{2}}{168 V_{0}^{3}}+\eta_{C} \frac{D^{C-S E C A}\left(V^{S}\right)^{2}}{168 V_{0}^{3}}+\eta_{N} \frac{\left(D-D^{S E C A}\right)\left(V^{S}\right)^{2}}{168 V_{0}^{3}}\right)\right)+\eta_{G} F^{A} N\right)
\end{gathered}
$$

where $\zeta_{S O_{x}}^{H}$ is the Sulfur emission factor of HFO, and $\eta_{G}, \eta_{C}$ and $\eta_{N}$ express the abatement efficiency of the scrubber system in different areas, respectively. In this study, the efficiency of the sulfur abatement is defined as the sulfur content ratio before and after the compliance option adopted. For example, the efficiency of the HFO ( $3.5 \%$ sulfur content) used in the scrubber system, is $0.5 / 3.5$ for areas with a sulfur limit of $0.5 \%$.

\subsection{Cost-Minimizing Process for Fuel-Switching Option}

Refer to Fan and Huang [11], combining Equations (1)-(4) and $N=W$, we can have the following Equation (25) which expresses the relationship between sailing speed inside and outside SECAs.

$$
V^{N-S E C A}=\frac{D-D^{G-S E C A}-D^{C-S E C A}}{168 N-P-\frac{D^{G-S E C A}}{V^{G-S E C A}}-\frac{D^{C-S E C A}}{V^{C-S E C A}}}
$$

It is obvious that the sailing speed is a function of operating number of vessels in the voyage. Therefore, the total daily costs are a function of the sailing speed. Due to the fact that the number of vessels is discrete, the common optimization method cannot be used to solve the model. In order to minimize the daily costs, a heuristic approach is proposed to find the optimal $V^{G-S E C A}, V^{C-S E C A}$, and $V^{N-S E C A}$ [11]. Firstly, the constant speed $V^{S}$ for a certain number of vessels in the voyage is attained by Equation (5). Second, a decreasing small pitch each time is applied in $V^{G-S E C A}$ and $V^{C-S E C A}$. Then $V^{N-S E C A}$ can be calculated by Equation (25) if the following conditions can be satisfied: $V^{G-S E C A}<V^{C-S E C A}<V^{S}$ and $V^{N-S E C A}>V^{S}$. It is worthwhile mentioning that if there is no difference between Chinese and global SECAs in sulfur limit regulations, then we have $V^{G-S E C A}=V^{C-S E C A}$. We repeat the process to calculate the respective speed and daily total costs, until the cost-minimizing combination of $V^{G-S E C A}, V^{C-S E C A}$ and $V^{N-S E C A}$ has been acquired. In the process, the number of operating vessels is the first input to get the constant sailing speed. 
The detail of cost-minimizing process is as follows:

1. We assume the initial speed sailing along the voyage is constant and the speed can be attained by Equation (5), where $V^{N-S E C A}=V^{G-S E C A}=V^{\mathrm{C}-S E C A}=V^{S}$.

2. According to Equations (14)-(16), the average total daily costs can be calculated.

3. Speed differentiation is a possible approach to reduce the total costs inside and outside SECAs with the fuel-switching option. Therefore, we have $V^{G-S E C A} \neq V^{N-S E C A}, V^{C-S E C A} \neq V^{N-S E C A}$ and $V^{G-S E C A}<V^{S}, V^{C-S E C A}<V^{S}$ and $V^{N-S E C A}>V^{S}$.

4. Using 'by trial and error' to calculate the particular $V^{G-S E C A}$ and $V^{N-S E C A}$ each time with a 0.1 pitch; $V^{C-S E C A}$ and $V^{N-S E C A}$ with a 0.2 pitch for different speed if there is an inconsistency sulfur cap between global and Chinese SECAs. Finally, the combination of different speed to minimize total daily costs can be found.

\subsection{Cost-Benefit Analysis of Two Sulfur Compliance Options}

Whether a compliance method will be chosen or not depends on their long-term costs and benefits due to enterprises chasing long-term profit maximization. Therefore, NPV analysis of different options can be used to compare their financial advantages. Refer to Corbett et al. [45], we have

$$
\pi_{i}=B_{i}-C T_{i}
$$

Since the operating earnings of a voyage service are related to the vessels fleet, capacity, the loading factor and specific freight rate, we have

$$
B_{i}=2 * n * N * V * L * F R
$$

where $n$ expresses the annual sailing times of each vessel and relies on the sailing speed and number of vessels in service.

The annual total costs in the voyage can be expressed in the following Equation (28).

$$
C T_{i}=\left(C T_{d, i} * \frac{D}{V^{S} * 24}+P\left(C B_{d, i}^{A}+C V_{d}\right)\right) n+C^{\text {main }} * N
$$

In Equation (28), the first term in the brackets is the annually total operating costs and the second term is the annual maintenance costs. It is worth mentioning that there are no annual maintenance costs for the fuel-switching option.

Then we have

$$
\pi_{i}=2 * n * N * V * L * F R-C T_{i}
$$

The NPV method is used to compare the cost-efficiency of the scrubber system and the fuel-switching options by the following equation.

$$
N P V^{i}=\sum_{t=0}^{Y} \frac{\pi_{i}}{(1+i)^{t}}-C A P E X^{i}
$$

where CAPEX is the initial investment and $\mathrm{Y}$ is the lifespan of the compliance option.

\section{Numerical Application}

\subsection{Chinese SECA}

China has already published several regulations about designating the coastal SECA which came into effect on 1 January, 2019. The new SECA range combines its previous SECAs together, i.e., Yangtze River Delta, Pearl River Delta, and Bohai Rim. In addition, potentially stricter regulations maybe come into effective in coastal areas especially after the implementation of 2020 global sulfur cap. 
The following Figure 2 illustrates the range of Chinese SECA. After 2020, Chinese government will assess and determine whether to adopt the $0.1 \%$ sulfur limit within Chinese SECA [4]. Therefore, the following section discusses whether the changing sulfur limit on Chinese SECA and the upcoming global sulfur cap will influence operators' compliance option choices during the vessel's lifespan.

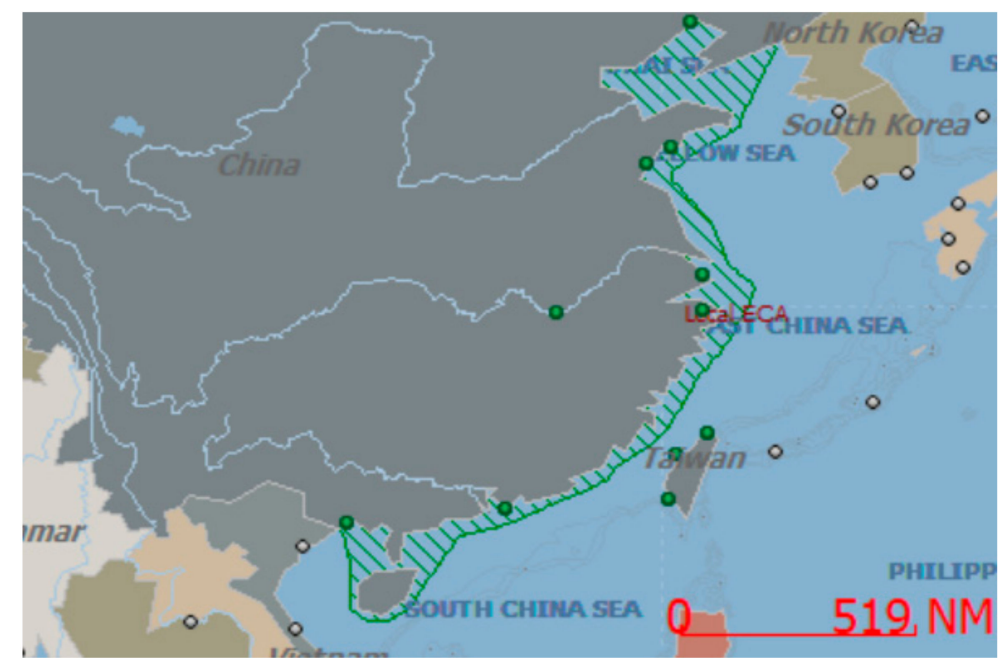

Figure 2. Chinese Local SECA.

\subsection{Case Assumptions}

Operators prefer a compliance option with higher long-term profits, which determines its operating condition and costs. To comply with corresponding emission regulations economically, shipowners must decide to whether adopting new technologies or not on newbuilding vessels, such as LNG, scrubber installation, or just switching fuels. As mention in the introduction, we mainly compare the scrubber system and the fuel-switching options in this study. Commonly, the lifespan of a scrubber system on newbuilding ships is 15 years [46]. The initial investment of a hybrid scrubber is $135 \$ / \mathrm{kW}$, meanwhile its annual maintenance costs is $1 \%$ of its total initial investments [46]. It can use the HFO with $3.5 \%$ sulfur content during its operation. The chemical treatment with magnesium oxide and seawater for the HFO will be considered to comply with the sulfur limit of $0.1 \%$, and the treatment with pure seawater will be utilized to satisfy the sulfur limit of $0.5 \%$. The price of magnesium oxide is 307 USD / ton, and $40 \mathrm{~kg}$ magnesium oxide powder (US \$12) is required for the treatment of one ton of HFO with 3.5\% sulfur content [47]. In the following analysis, a specific route across Chinese and global SECAs is chosen to compare the compliance strategies with different sulfur limit scenarios. According to the Clarkson's Shipping Intelligence Network (SIN) in July, 2019, the prices of three different bunkers are $\$ 435$ (HFO), $\$ 500$ (ULSFO), and $\$ 630$ (MGO) for each ton.

The following Table 2 lists the emission factors of $\mathrm{CO}_{2}$ and $\mathrm{SO}_{\mathrm{x}}$ for different bunkers, which is compiled from the third IMO GHG study [48] and Kontovas [49].

Table 2. Emission factors for different bunkers.

\begin{tabular}{ccc}
\hline \multirow{2}{*}{ Fuel Type } & \multicolumn{2}{c}{ Emission Factors (g/g of Fuel) } \\
\cline { 2 - 3 } & $\mathbf{C O}_{\mathbf{2}}$ & $\mathbf{S O}_{\mathbf{x}}$ \\
\hline $\mathrm{HFO}(3.5 \%)$ & 3.114 & 0.07 \\
$\mathrm{ULSFO}(0.5 \%)$ & 3.206 & 0.01 \\
$\operatorname{MGO}(0.1 \%)$ & 3.206 & 0.002 \\
\hline
\end{tabular}




\subsection{Scenarios on Increasingly Strict Sulfur Limit}

Currently, the sulfur limit in Chinese SECA is $0.5 \%$, while it is $0.1 \%$ for global SECAs. The current limit of the sulfur content outside any SECAs cannot surpass 3.5\%, which came into effect from 2013. As the global sulfur content cap of $0.1 \%$ will be implemented after 1 January, 2020, the compliance choices may be different due to the higher compliance and operating costs. In addition, the sulfur regulation of Chinese SECA $(0.5 \%)$ is lagging behind of the other SECAs $(0.1 \%)$, which could be more stringent accordingly. Based on the model introduced in Section 3, the compliance choice behavior of operators can be analyzed under the increasingly strict sulfur regulations. Therefore, the following four different scenarios under various sulfur regulations will be analyzed to explore their impacts on the choices of compliance options.

1. The sulfur limit in global SECAs is $0.1 \%$ and $0.5 \%$ in Chinese SECA, while it is $3.5 \%$ on the high seas, which is the current situation.

2. The sulfur limit in global and Chinese SECAs is $0.1 \%$, while it is $3.5 \%$ on the high seas.

3. The sulfur limit in global SECAs is $0.1 \%$, and it is $0.5 \%$ in Chinese SECA and on the high seas.

4. The sulfur limit in global and Chinese SECAs is $0.1 \%$, while it is $0.5 \%$ outside these areas.

\subsection{Considered Line Services}

The model in Section 3 is applied in a container liner service from Qingdao to Rotterdam (East Asia-North Europe), and the detailed information is listed in Table 3.

Table 3. Service information for the line from Qingdao to Rotterdam

\begin{tabular}{|c|c|}
\hline \multicolumn{2}{|l|}{ The Service Information. } \\
\hline Vessel capacity (TEU) $^{1}$ & 10,106 \\
\hline Main engine power $(\mathrm{kW})^{1}$ & 84,582 \\
\hline Auxiliary engine power $(\mathrm{kW})^{1}$ & 3750 \\
\hline Design speed (knots) ${ }^{1}$ & 24 \\
\hline Round-trip Distance (nautical miles) ${ }^{2}$ & 21,874 \\
\hline Distance in global SECA (nautical miles) ${ }^{2}$ & 836 \\
\hline Distance in China SECA (nautical miles) & 94 \\
\hline Freight rate ${ }^{4}$ & 630 \\
\hline Number of calls in round-trip & 12 \\
\hline Average call time in a port (day) & 1 \\
\hline Crew $(\$ / \text { day })^{3}$ & 3137 \\
\hline Repair and maintenance (\$/day) ${ }^{3}$ & 4485 \\
\hline Insurance $(\$ / \text { day })^{3}$ & 1825 \\
\hline Store and lube $(\$ / \text { day })^{3}$ & 3739 \\
\hline Administration (\$/day) ${ }^{3}$ & 665 \\
\hline Capital costs $(\$ / \text { day })^{3}$ & 31,459 \\
\hline Total: Fixed daily costs (\$/day) & 45,330 \\
\hline
\end{tabular}

The specific service line is Qingdao-Shanghai-Ningbo-Singapore-LeHavre-Rotterdam-HamburgDunkirk-Malta-Port Kelang-Singapore-Qingdao, which shows in Figure 3. The distance inside and outside SECAs can be attained using the Netpas software, which consists of extensive ports and all SECAs. As discussed in Section 3, the number of service vessels is a key input in speed optimization and cost-minimizing procedure for the fuel-switching option. After determining the number of service vessels, we can get the specific sailing speed within different areas of the two compliance options. 


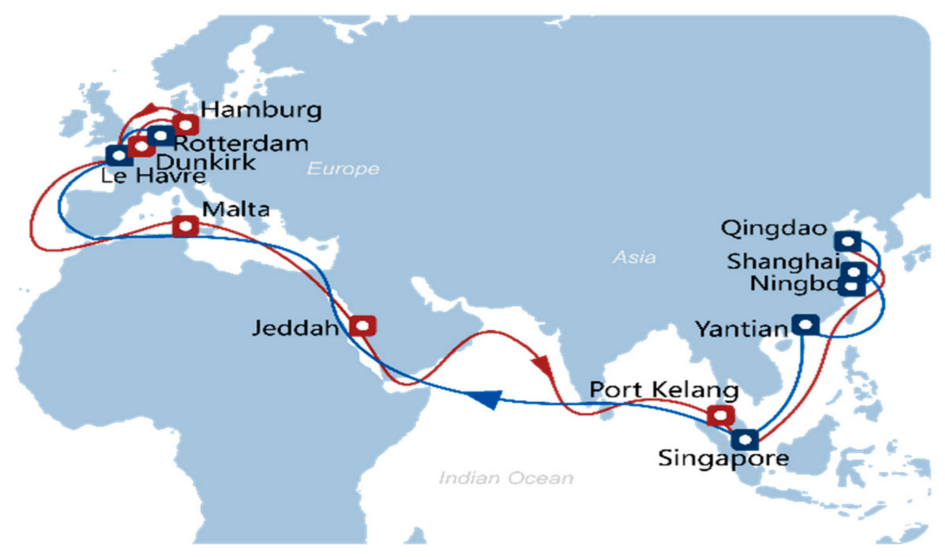

Figure 3. Specific route of China to Northern Europe.

\subsection{Numerical Results}

The following Table 4 details the numerical results under different Sulfur limit scenarios using the model introduced in Section 3. We can see that the scrubber system has lower daily costs in all scenarios due to the continuous use of HFO. However, the present value of the scrubber investment cost is huge, which results in a higher total cost for the scrubber installation option. Therefore, the fuel-switching option is more cost-efficiency under Scenario 1 and 2. This is because of the short distance of global and Chinese SECAs in the whole line, which only accounts for $4.3 \%$ in the total distance

In terms of the other scenarios with stricter global sulfur cap, i.e., $0.5 \%$ Sulfur cap regulation on global high seas, the compliance choice changes owing to the truth that more low-sulfur oil has to be used in the whole cycle. The scrubber system shows its advantages during the vessels' lifespan when a stricter sulfur cap is effective in a large scale. In Scenario 3, the sulfur cap of $0.1 \%$ is required in global SECAs and $0.5 \%$ within Chinese SECA and global high seas, which is the most possible situation in 2020. The result shows that the scrubber system is more economic after the 10 th year. In Scenario 4 , the sulfur cap of $0.1 \%$ is assumed in all SECAs and $0.5 \%$ on global high seas, which is stricter than Scenario 3. The result suggests that the daily costs increase with the increasingly strict sulfur policy and the advantageous year of the scrubber installation option will begin from the 8th year. Through the discussion, we can see that the stricter the sulfur regulations, the higher the priority of installing scrubbers due to the more cost-savings by using high-sulfur fuel (lower in price).

The speed differentiation in the fuel-switching option is also analyzed under four scenarios in Table 4. We find that the variation of speed in different areas is smaller under the latter two scenarios. This may be due to the relatively narrow distance within SECAs in the cycle, and the smaller price spread between the low-sulfur oils, i.e., oils with sulfur content of $0.1 \%$ and $0.5 \%$. These could be further investigated in the future. The last observation from the numerical analysis in Table 4 is about the emission abatement efficiency of the two options. All scenarios confirm the higher abatement efficiency of the scrubber system on $\mathrm{SO}_{\mathrm{x}}$ emission. In terms of $\mathrm{CO}_{2}$ emission, the scrubber system has a higher value comparing with the fuel-switching option due to more energy consumption in the scrubber system, which is consistent with the result acquired by Abadie et al. [26]. The differences of emissions and total daily costs for two compliance options are listed ( $\Delta$ Daily cost, $\Delta \mathrm{CO}_{2}$, and $\Delta \mathrm{SO}_{\mathrm{x}}$ ), which shows the variations between the fuel-switching and scrubber system. Obviously, stricter sulfur caps can reduce sulfur emissions in both compliance options. However, it does not work for carbon emissions. Actually, it increases the carbon emission, which urges the renegotiation of environmental policies for shipping activities. 
Table 4. Numerical results of the model for different sulfur limit scenarios

\begin{tabular}{|c|c|c|c|c|c|c|c|c|c|c|c|c|c|c|c|c|}
\hline \multicolumn{8}{|c|}{ Fuel-Switching } & \multicolumn{5}{|c|}{ Scrubber System } & \multicolumn{4}{|c|}{ Results Comparison } \\
\hline \multirow{2}{*}{ Scenarios } & $V^{G-S E C A}$ & $V^{C-S E C A}$ & $V^{\mathrm{N}-S E C A}$ & Daily cost & $\begin{array}{l}\text { Cumulative } \\
\text { NPV }\end{array}$ & $\mathrm{CO}_{2}$ & $\mathrm{SO}_{x}$ & $V^{S}$ & Daily cost & $\begin{array}{l}\text { Cumulative } \\
\text { NPV }\end{array}$ & $\mathrm{CO}_{2}$ & $\mathrm{SO}_{\mathrm{x}}$ & \multirow{2}{*}{$\begin{array}{c}\Delta \text { Daily } \\
\operatorname{cost}(\%)^{2}\end{array}$} & $\Delta \mathrm{CO}_{2}{ }^{2}$ & $\Delta \mathrm{SO}_{x}{ }^{2}$ & \multirow{2}{*}{ Option $^{1}$} \\
\hline & (Knots) & (Knots) & (Knots) & (\$/day) & (Million) & (Tons) & (Tons) & (Knots) & (\$/Day) & (Million) & (Tons) & (Tons) & & $(\%)$ & $(\%)$ & \\
\hline 1 & 15.87 & 16.87 & 17.97 & $908,997.1$ & 2063 & 3428.96 & 68.44 & \multirow{4}{*}{17.87} & $889,584.2$ & 1955 & \multirow{4}{*}{3446.44} & 68.42 & 2.14 & -0.51 & 0.03 & Fuel-switching \\
\hline 2 & 15.87 & 17.97 & 17.97 & 909,474 & 1966 & 3429.37 & 68.43 & & $889,590.1$ & 1857 & & 68.39 & 2.19 & -0.5 & 0.06 & Fuel-switching \\
\hline 3 & 17.17 & 17.9 & 17.9 & 972,401 & 1895 & 3425.56 & 10.14 & & $889,584.2$ & 1955 & & 10.03 & 8.52 & -0.61 & 1.08 & Scrubber \\
\hline 4 & 16.57 & 16.57 & 17.93 & $972,662.6$ & 1805 & 3426.27 & 10 & & $889,590.1$ & 1955 & & 9.96 & 8.54 & -0.59 & 0.4 & Scrubber \\
\hline
\end{tabular}

Note: ${ }^{1}$ It suggests the most economic option in the lifespan under four different scenarios. ${ }^{2}$ The percentages are calculated as the difference between the two options to the value of the scrubber option.

Table 5. Numerical results of changing deployed vessels for Scenario 3

\begin{tabular}{|c|c|c|c|c|c|c|c|c|c|c|c|c|c|c|}
\hline \multicolumn{7}{|c|}{ Fuel-Switching } & \multicolumn{5}{|c|}{ Scrubber System } & \multicolumn{3}{|c|}{ Results Comparison } \\
\hline \multirow[t]{2}{*}{$\mathbf{N}$} & $V^{G-S E C A}$ & $\begin{array}{l}V^{C-S E C A} / \\
V^{N-S E C A}\end{array}$ & Daily cost & $\begin{array}{c}\text { Cumulative } \\
\text { NPV }\end{array}$ & $\mathrm{CO}_{2}$ & $\mathrm{SO}_{\mathrm{x}}$ & $V^{S}$ & $\begin{array}{l}\text { Daily } \\
\text { Cost }\end{array}$ & $\begin{array}{c}\text { Cumulative } \\
\text { NPV }\end{array}$ & $\mathrm{CO}_{2}$ & $\mathrm{SO}_{\mathrm{x}}$ & $\Delta \mathrm{CO}_{2}$ & $\Delta \mathrm{SO}_{\mathrm{x}}$ & \multirow[t]{2}{*}{ Year $^{1}$} \\
\hline & (Knots) & (Knots) & (\$/Day) & (Million) & (Tons) & (Tons) & (Knots) & (\$/Day) & (Million) & (Tons) & (Tons) & $(\%)$ & $(\%)$ & \\
\hline 8 & 19.91 & 20.75 & $1,095,314$ & 1471 & 4471.73 & 13.56 & 20.71 & $991,747.9$ & 1566 & 4502.29 & 13.4 & -0.68 & 1.18 & 8 \\
\hline 9 & 17.17 & 17.9 & 972,401 & 1895 & 3425.56 & 10.14 & 17.87 & $889,584.2$ & 1955 & 3446.44 & 10.03 & -0.61 & 1.08 & 10 \\
\hline 10 & 15.71 & 15.74 & 908,765 & 2230 & 2745.53 & 7.88 & 15.71 & $839,005.82$ & 2263 & 2759.87 & 7.82 & -0.52 & 0.76 & 12 \\
\hline 11 & 13.52 & 14.04 & 880,311 & 2492 & 2282.8 & 6.3 & 14.02 & $819,043.06$ & 2504 & 2292.47 & 6.26 & -0.42 & 0.63 & 14 \\
\hline
\end{tabular}

Note: ${ }^{1}$ It suggests the year when the NPVs of profits with the scrubber installation option can surpass that of the fuel-switching option. 
As discussed in the model, the vessels' sailing speed can be changed according to the number of deployed vessels in the line. Table 5 reports the comparison between the two compliance options with different numbers of deployed vessels using Scenario 3, as which is the most possible situation in 2020. The result shows that the average daily costs will be reduced when additional vessels are operated in the liner service, which is due to the fact that the smaller operating speed leads to lower bunker consumption, and thereby with lower emissions for both $\mathrm{CO}_{2}$ and $\mathrm{SO}_{\mathrm{x}}$. From the standpoint of sulfur emissions, the scrubber system option has a higher efficiency of emission abatement compares with the fuel-switching option. In addition, the specific year when NPVs of the scrubber system can surpass that of the fuel-switching option is explored with different number of deployed ships. The last column in Table 5 shows the year when the scrubber system showing its advantage. It is obvious that more deployed number of vessels will postpone the advantage of installing scrubbers.

Actually, there are intensive studies on the determining factors of investment decisions under sulfur caps, and most of them argue that the distance spending within SECAs and oil price difference are critical $[26,45,52,53]$. However, the case selected in this study is a long-distance liner route where the SECA distance only accounts for $4.4 \%$ of the whole service. Even if there is a potential that Chinese SECA will be expanded and the designation of the other SECAs, the main portion of the route is still on the high seas. Therefore, the SECA distance would not be the most important factor that determines operators' compliance option choices in the case.

Seeing from the model and the results in Tables 4 and 5, the price difference of low and high-sulfur oils has an overall impact on operators' compliance decisions. The following Figure 4 illustrates the influence of price difference between low and high-sulfur bunkers with different sulfur content based on Scenario 4 (the strictest situation in our study). The letters in brackets represent the level of oil price differences between ULSFO and HFO where the price of HFO is the reference ( $\$ 435 /$ ton) for comparison. We define $\mathrm{L}$ as a low oil price difference of $\$ 35$ between them, and $\mathrm{H}$ as a high oil price difference of $\$ 100$. The following Figure 4 shows that the advantageous year of the scrubber system advanced to the 7 th year with a higher oil price difference. However, it is never cost-efficiency to install scrubbers with low oil price difference during the vessels' lifespan.

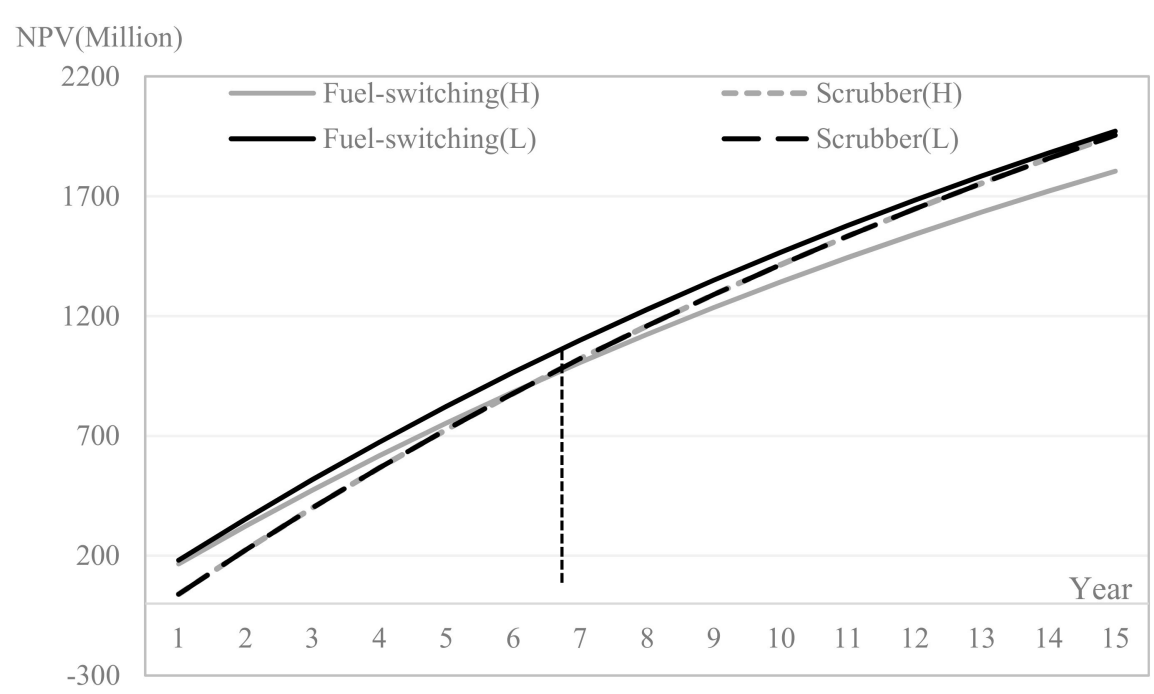

Figure 4. NPVs for different price differences between low and high sulfur fuels.

\section{Conclusions}

The shipping industry has been under intensive environmental pressure for satisfying more stringent environmental regulations. It can be traced back to the efforts by IMO to protect human health and environment, especially for coastal citizens. The upcoming 2020 sulfur cap requires operators to select a suitable and economic compliance option complying with the new sulfur regulation. In practice, sulfur cap regulations require either the use of low-sulfur fuel such as MGO or LNG, or the scrubber 
on newbuilding or retrofitting vessels. The former option increases the demand for compliance fuels while the latter alternative continuously enables vessels to operate with cheap fuels, such as HFO. In addition to the globally recognized SECAs, some domestic SECAs are also under discussion or in an experimental stage, such as Chinese SECA. Although huge differences on the range and standards between Chinese and the other SECAs exist, the Chinese authorities are intending to strengthen the restriction along with the global sulfur cap 2020. These increasingly stricter regulations will definitely impact the operation of shipping companies.

Therefore, this study explores the compliance options of operators based on NPV analysis and cost-optimization method between fuel-switching and scrubber system options. To analyze operators' responses more precisely, the slow steaming practice within SECAs and speeding up outside SECAs are incorporated into the model for the fuel-switching option. In the case study, the comparison of two options are carried out under different sulfur limit scenarios. Theoretically speaking, the study confirms that sulfur limit regulation is an effective way to reduce shipping externalities and improve the marine environment as well as public health. The impacts can be strengthened with the increasingly stringent sulfur caps in the future. Meanwhile, the stricter sulfur regulations also pose some threats to shipping industry, which consists of demands for technological innovations and compliance fuels, etc. The following results can be attained: first, the upcoming 2020 global sulfur cap greatly influences operators' compliance option choices. From the standpoint of operators, the stringent global sulfur cap refers to more compliance costs paid by operators. Furthermore, the scrubber installation option will gain more attractiveness and priority with a stricter sulfur limit on the global high seas due to the energy cost-savings. The increasingly stringent sulfur limit regulations not only increase the costs of operators, but also press on the related sectors, such as refineries and equipment producers, which also should be on policymakers' agenda. Whether the related sectors can provide timely supply of compliance oils or equipment is the main concern of policymakers in shipping industry. Second, it is noteworthy that the effects of speed differentiation are limited in the selected case owing to the smaller SECA range in the cycle. Third, the scrubber system has a higher emission of $\mathrm{CO}_{2}$ but can reduce more sulfur emission in comparison with the fuel-switching option. IMO aims to reduce shipping emissions and supervise the shipping activities from different aspects, which not only include sulfur emission. In other words, emission reduction from shipping should be an overall approach, which should not at the expense of increasing other pollutants. From the perspective of policymakers, the additional carbon emissions must be considered, especially for the purpose of reducing half carbon emissions till 2050 proposed by IMO. Besides, whether scrubber system is the most environmental-friendly approach to control sulfur emission still needs further consideration. Last but not least, additional vessels deployed in the cycle can save bunker costs due to lower operating costs. However, when more ships are deployed on the line, the advantages of installing scrubbers are reduced due to excessive initial investments. Some governments fund the investment of compliance options encouraging operating companies to adopt positive actions for environmental regulations, which can be referential experience by some policymakers. It is worthwhile mentioning that when emission reduction regulations become stricter, such as the implementation of the global sulfur cap 2020, the scrubber system is an economic option to operators.

The model used in the study can be extended to different lines and vessels even after 2020 for operators or shipowners choosing compliance option choices, which contains initial investments and operating costs on particular vessels and compliance options. Therefore, it is possible to solve similar issues where there are alternatives between equipment investments and operating costs.

As for the limitations and future directions in the study, they can be listed as follows. First, this study only discusses the sulfur emission and operators' compliance choices, which can be extended to the other emissions. Second, the calculations of emissions in the study is dependent on emission factors and the real sailing situation, which can be modeled more precisely in the future. Third, some parameters are assumed constant within the vessel's lifespan, which can be relaxed in the future. 
Author Contributions: Conceptualization, L.F. and B.G.; Formal analysis, B.G.; Funding acquisition, L.F.; Methodology, B.G.; Project administration, L.F; Resources, B.G.; Supervision, L.F.; Writing-review and editing, B.G. and L.F. All authors have read and agreed to the published version of the manuscript.

Funding: This research is supported by the National Natural Science foundation of China $(71673181,71831008)$ and the National Social Science Fund of China (17BGL259).

Conflicts of Interest: The authors declare no conflict of interest.

\section{References}

1. Halim, R.A.; Kirstein, L.; Merk, O.; Martinez, L.M. Decarbonization pathways for international maritime transport: A model-based policy impact assessment. Sustainability 2018, 10, 2243. [CrossRef]

2. Canbulat, O.; Aymelek, M.; Turan, O.; Boulougouris, E. An application of BBNs on the integrated energy efficiency of ship-port interface: A dry bulk shipping case. Marit. Policy Manag. 2019, 46, 845-865. [CrossRef]

3. Zis, T.; Psaraftis, H. Operational measures to mitigate and reverse the potential modal shifts due to environmental legislation. Marit. Policy Manag. 2018, 46, 117-132. [CrossRef]

4. Chen, J.; Wan, Z.; Zhang, H.; Liu, X.; Zhu, Y.; Zheng, A. Governance of shipping emission of $\mathrm{SO}_{\mathrm{x}}$ in $\mathrm{China}^{\prime} \mathrm{s}$ coastal waters: The SECA policy, challenges, and directions. Coast. Manag. 2018, 46, 191-209. [CrossRef]

5. Zhang, Y.Q.; Loh, C.; Louie, P.K.K.; Li, H.; Lau, A.K.H. The roles of scientific research and stakeholder engagement for evidence-based policy formulation on shipping emissions control in Hong Kong. J. Environ. Manag. 2018, 223, 49-56. [CrossRef] [PubMed]

6. Vanek, F. Mode and commodity perspectives on US freight energy consumption and $\mathrm{CO}_{2}$ emissions: Insights and directions for improvement. Int. J. Sustain. Transp. 2019, 13, 741-760. [CrossRef]

7. Chang, Y.-T.; Roh, Y.; Park, H. Assessing noxious gases of vessel operations in a potential emission control area. Transp. Res. Part D Transp. Environ. 2014, 28, 91-97. [CrossRef]

8. Cariou, $\mathrm{P}$. Is slow steaming a sustainable means of reducing $\mathrm{CO}_{2}$ emissions from container shipping? Transp. Res. Part D Transp. Environ. 2011, 16, 260-264. [CrossRef]

9. Chen, L.; Yip, T.L.; Mou, J. Provision of Emission Control Area and the impact on shipping route choice and ship emissions. Transp. Res. Part D-Transp. Environ. 2018, 58, 280-291. [CrossRef]

10. Merien-Paul, R.H.; Enshaei, H.; Jayasinghe, S.G. Effects of fuel-specific energy and operational demands on cost/emission estimates: A case study on heavy fuel-oil vs liquefied natural gas. Transp. Res. Part D-Transp. Environ. 2019, 69, 77-89. [CrossRef]

11. Fan, L.X.; Huang, L.Y. Analysis of the Incentive for Slow Steaming in Chinese Sulfur Emission Control Areas. Transp. Res. Rec. 2019, 2673, 165-175. [CrossRef]

12. Zhen, L.; Li, M.; Hu, Z.; Lv, W.; Zhao, X. The effects of emission control area regulations on cruise shipping. Transp. Res. Part D Transp. Environ. 2018, 62, 47-63. [CrossRef]

13. Topali, D.; Psaraftis, H.N. The enforcement of the global sulfur cap in maritime transport. Marit. Bus. Rev. 2019, 4, 199-216. [CrossRef]

14. Lindstad, H.; Sandaas, I.; Stromman, A.H. Assessment of cost as a function of abatement options in maritime emission control areas. Transp. Res. Part D Transp. Environ. 2015, 38, 41-48. [CrossRef]

15. Yoo, B.Y. Economic assessment of liquefied natural gas (LNG) as a marine fuel for $\mathrm{CO}_{2}$ carriers compared to marine gas oil (MGO). Energy 2017, 121, 772-780. [CrossRef]

16. Winebrake, J.J.; Corbett, J.J.; Umar, F.; Yuska, D. Pollution Tradeoffs for Conventional and Natural Gas-Based Marine Fuels. Sustainability 2019, 11, 2235. [CrossRef]

17. Doudnikoff, M.; Lacoste, R. Effect of a speed reduction of containerships in response to higher energy costs in Sulphur Emission Control Areas. Transp. Res. Part D Transp. Environ. 2014, 28, 51-61. [CrossRef]

18. Shipping Intelligence Network. Available online: https://sin.clarksons.net/ (accessed on 1 September 2019).

19. Van Wee, B.; Roeser, S. Ethical theories and the cost-benefit analysis-based Ex ante evaluation of transport policies and plans. Transp. Rev. 2013, 33, 743-760. [CrossRef]

20. Tran, T.M.T.; Yuen, K.F.; Li, K.X.; Balci, G.; Ma, F. A theory-driven identification and ranking of the critical success factors of sustainable shipping management. J. Clean. Prod. 2020, 243, 14. [CrossRef]

21. Yuen, K.F.; Wang, X.Q.; Wong, Y.D.; Zhou, Q.J. The effect of sustainable shipping practices on shippers' loyalty: The mediating role of perceived value, trust and transaction cost. Transp. Res. Part E Logist. Transp. Rev. 2018, 116, 123-135. [CrossRef] 
22. Yuen, K.F.; Li, K.X.; Xu, G.Y.; Wang, X.Q.; Wong, Y.D. A taxonomy of resources for sustainable shipping management: Their interrelationships and effects on business performance. Transp. Res. Part E Logist. Transp. Rev. 2019, 128, 316-332. [CrossRef]

23. Nikcevic, J. Strengthening the role of local government to ensure sustainable development of the cruise sector: The case of Kotor. Mar. Policy 2019, 109, 12. [CrossRef]

24. Schinas, O.; Stefanakos, C.N. Cost assessment of environmental regulation and options for marine operators. Transp. Res. Part C Emerg. Technol. 2012, 25, 81-99. [CrossRef]

25. Schinas, O.; Stefanakos, C.N. Selecting technologies towards compliance with MARPOL Annex VI: The perspective of operators. Transp. Res. Part D 2014, 28, 28-40. [CrossRef]

26. Abadie, L.M.; Goicoechea, N.; Galarraga, I. Adapting the shipping sector to stricter emissions regulations: Fuel switching or installing a scrubber? Transp. Res. Part D Transp. Environ. 2017, 57, 237-250. [CrossRef]

27. Chang, Y.-T.; Park, H.K.; Lee, S.; Kim, E. Have Emission Control Areas (ECAs) harmed port efficiency in Europe? Transp. Res. Part D Transp. Environ. 2018, 58, 39-53. [CrossRef]

28. Lin, Y.; Yan, L.Z.; Wang, Y.M. Performance Evaluation and Investment Analysis for Container Port Sustainable Development in China: An Inverse DEA Approach. Sustainability 2019, 11, 4617. [CrossRef]

29. Zis, T.; Psaraftis, H.N. The implications of the new sulphur limits on the European Ro-Ro sector. Transp. Res. Part D Transp. Environ. 2017, 52, 185-201. [CrossRef]

30. Svindland, M. The environmental effects of emission control area regulations on short sea shipping in Northern Europe: The case of container feeder vessels. Transp. Res. Part D Transp. Environ. 2018, 61, 423-430. [CrossRef]

31. Lähteenmäkiuutela, A.; Repka, S.; Haukioja, T.; Pohjola, T. How to recognize and measure the economic impacts of environmental regulation: The Sulphur Emission Control Area case. J. Clean. Prod. 2017, 154, 553-565. [CrossRef]

32. Brynolf, S.; Magnusson, M.; Fridell, E.; Andersson, K. Compliance possibilities for the future ECA regulations through the use of abatement technologies or change of fuels. Transp. Res. Part D Transp. Environ. 2014, 28, 6-18. [CrossRef]

33. Jiang, L.; Kronbak, J.; Christensen, L.P. The costs and benefits of sulphur reduction measures: Sulphur scrubbers versus marine gas oil. Transp. Res. Part D 2014, 28, 19-27. [CrossRef]

34. Zis, T. Prospects of cold ironing as an emissions reduction option. Transp. Res. Part A Policy Pract. 2019, 119, 82-95. [CrossRef]

35. Ammar, N.R.; Seddiek, I.S. Eco-environmental analysis of ship emission control methods: Case study RO-RO cargo vessel. Ocean Eng. 2017, 137, 166-173. [CrossRef]

36. Yang, Z.L.; Zhang, D.; Caglayan, O.; Jenkinson, I.D.; Bonsall, S.; Wang, J.; Huang, M.; Yan, X.P. Selection of techniques for reducing shipping $\mathrm{NOx}$ and $\mathrm{SO}_{\mathrm{x}}$ emissions. Transp. Res. Part D Transp. Environ. 2012, 17, 478-486. [CrossRef]

37. Yin, J.; Fan, L.; Yang, Z.; Li, K.X. Slow steaming of liner trade: Its economic and environmental impacts. Marit. Policy Manag. 2014, 41, 149-158. [CrossRef]

38. Gu, Y.; Wallace, S.W.; Wang, X. Integrated Maritime Fuel Management with Stochastic Fuel Prices and New Emission Regulations. J. Operat. Res. Soc. 2018, 1-19. [CrossRef]

39. Panagakos, G.P.; Stamatopoulou, E.V.; Psaraftis, H.N. The possible designation of the Mediterranean Sea as a SECA: A case study. Transp. Res. Part D Transp. Environ. 2014, 28, 74-90. [CrossRef]

40. Cariou, P.; Cheaitou, A. The effectiveness of a European speed limit versus an international bunker-levy to reduce $\mathrm{CO}_{2}$ emissions from container shipping. Transp. Res. Part D Transp. Environ. 2012, 17, 116-123. [CrossRef]

41. Psaraftis, H.N. Market-based measures for greenhouse gas emissions from ships: A review. WMU J. Marit. Aff. 2012, 11, 211-232. [CrossRef]

42. Nikopoulou, Z.; Cullinane, K.; Jensen, A. The role of a cap-and-trade market in reducing $\mathrm{NO}_{\mathrm{x}}$ and $\mathrm{SO}_{\mathrm{x}}$ emissions: Prospects and benefits for ships within the Northern European ECA. Proc. Inst. Mech. Eng. Part M J. Eng. Marit. Environ. 2013, 227, 136-154. [CrossRef]

43. Wang, K.; Fu, X.; Luo, M. Modeling the impacts of alternative emission trading schemes on international shipping. Transp. Res. Part A Policy Pract. 2015, 77, 35-49. [CrossRef]

44. Koesler, S.; Achtnicht, M.; Kohler, J. Course set for a cap? A case study among ship operators on a maritime ETS. Transp. Policy 2015, 37, 20-30. [CrossRef] 
45. Corbett, J.J.; Wang, H.; Winebrake, J.J. The effectiveness and costs of speed reductions on emissions from international shipping. Transp. Res. Part D Transp. Environ. 2009, 14, 593-598. [CrossRef]

46. Gu, Y.; Wallace, S.W. Scrubber: A potentially overestimated compliance method for the Emission Control Areas The importance of involving a ship's sailing pattern in the evaluation. Transp. Res. Part D Transp. Environ. 2017, 55, 51-66. [CrossRef]

47. Zhang, D.D.; Wang, L.N.; Wu, C.F.; Dai, J.J.; Gao, Z.Y. Economic analysis of three options to the new regulation of fuel sulfur limitation in shipping industry. Int. Oil Econ. 2019, 27, 48-53.

48. International Maritime Organization. Available online: http://www.imo.org/en/OurWork/Environment/ PollutionPrevention/AirPollution/Pages/Greenhouse-Gas-Studies-2014.aspx (accessed on 23 December 2019).

49. Kontovas, C.A. The Green Ship Routing and Scheduling Problem (GSRSP): A conceptual approach. Transp. Res. Part D Transp. Environ. 2014, 31, 61-69. [CrossRef]

50. World Fleet Register. Available online: https://www.clarksons.net/wfr/ (accessed on 1 September 2019).

51. Netpas, D. Netpas Distance; Netpas: Seoul, Korea, 2019.

52. UNCTAD. Review of Maritime Transport; United Nations: New York, NY, USA; Geneva, Switzerland, 2018.

53. Åström, S.; Yaramenka, K.; Winnes, H.; Fridell, E.; Holland, M. The costs and benefits of a nitrogen emission control area in the Baltic and North Seas. Transp. Res. Part D Transp. Environ. 2018, 59, 223-236. [CrossRef]

(C) 2019 by the authors. Licensee MDPI, Basel, Switzerland. This article is an open access article distributed under the terms and conditions of the Creative Commons Attribution (CC BY) license (http://creativecommons.org/licenses/by/4.0/). 